Article

\title{
Joining of TiAl to Steel by Diffusion Bonding with Ni/Ti Reactive Multilayers
}

\author{
Sónia Simões ${ }^{1}$, Ana S. Ramos ${ }^{2}$, Filomena Viana ${ }^{1}$, Maria Teresa Vieira ${ }^{2}$ and Manuel F. Vieira ${ }^{1, *}$ \\ 1 CEMUC, Department of Metallurgical and Materials Engineering, University of Porto, R. Dr. Roberto Frias, \\ Porto 4200-465, Portugal; ssimoes@fe.up.pt (S.S.); fviana@fe.up.pt (F.V.) \\ 2 CEMUC, Department of Mechanical Engineering, University of Coimbra, R. Luís Reis Santos, \\ Coimbra 3030-788, Portugal; sofia.ramos@dem.uc.pt (A.S.R.); teresa.vieira@dem.uc.pt (M.T.V.) \\ * Correspondence: mvieira@fe.up.pt; Tel.: +351-225081424; Fax: +351-220414900
}

Academic Editor: Hugo F. Lopez

Received: 2 March 2016; Accepted: 20 April 2016; Published: 25 April 2016

\begin{abstract}
Dissimilar diffusion bonds of TiAl alloy to AISI 310 stainless steel using Ni/Ti reactive multilayers were studied in this investigation. The $\mathrm{Ni}$ and $\mathrm{Ti}$ alternating layers were deposited by d.c. magnetron sputtering onto the base materials, with a bilayer thickness of 30 and $60 \mathrm{~nm}$. Joining experiments were performed at 700 and $800{ }^{\circ} \mathrm{C}$ for $60 \mathrm{~min}$ under pressures of 50 and $10 \mathrm{MPa}$. The effectiveness of using Ni/Ti multilayers to improve the bonding process was assessed by microstructural characterization of the interface and by mechanical tests. Diffusion bonded joints were characterized by scanning electron microscopy (SEM), energy dispersive X-ray spectroscopy (EDS), electron backscatter diffraction (EBSD), transmission electron microscopy (TEM) and selected area electron diffraction (SAED), high resolution TEM (HRTEM) and Fast Fourier transform (FFT). The bonding interfaces are thin (approximately $5 \mu \mathrm{m}$ thick) with a layered microstructure. For all joints, the interface is mainly composed of equiaxed grains of NiTi and $\mathrm{NiTi}_{2}$. The thickness and number of layers depends on the joining conditions and bilayer thickness of the multilayers. Mechanical characterization of the joints was performed by nanoindentation and shear tests. Young's modulus distribution maps highlight the phase differences across the joint's interface. The highest shear strength value is obtained for the joint produced at $800{ }^{\circ} \mathrm{C}$ for 60 min under a pressure of $10 \mathrm{MPa}$ using Ni/Ti multilayers with $30 \mathrm{~nm}$ of bilayer thickness.
\end{abstract}

Keywords: diffusion bonding; TiAl; stainless steel; multilayers

\section{Introduction}

The development of TiAl intermetallics has attracted the interest of several researchers due to its unique properties, which are suitable for a wide field of applications. However, a limiting factor for the integration of TiAl into structures is the lack of reliable and efficient joining techniques, especially for dissimilar joints. Dissimilar joining of these alloys is very difficult, due to their high reactivity and the tendency to form brittle intermetallic phases [1,2]. The development of joining technologies has become an essential requirement for application of these alloys in replacing traditional metallic alloys in aerospace and automotive applications [3-6]. However, there are only a few reports regarding the techniques used to join TiAl alloys with other materials [6-12].

The joining of TiAl and steel is relevant for some applications, in particular for missile and tank engine turbo components. The use of fusion welding techniques to join TiAl to steel promotes the formation of brittle phases, $\mathrm{TiC}$ and Ti-Fe intermetallics, and high residual stress produced during solidification, leading to weak joints $[4,5]$.

Diffusion bonding is one of the most promising processes for successfully joining TiAl to steel with high mechanical properties, avoiding the problems associated with fusion welding processes. 
Dissimilar joints can be produced by direct diffusion bonding of TiAl to steel at $850-1000{ }^{\circ} \mathrm{C}$ for 1 to $60 \mathrm{~min}$ under a pressure ranging from 5 to $40 \mathrm{MPa}$ [9]. Close to the TiAl base material, the interfaces are composed of $\mathrm{Ti}_{3} \mathrm{Al}+\mathrm{FeAl}+\mathrm{FeAl}_{2}$ intermetallic compounds. The specimens bonded at low temperature exhibit very low tensile strength (18 MPa); a maximum tensile strength of 170-185 MPa was measured for the optimum bond conditions $\left(930-960{ }^{\circ} \mathrm{C}\right.$ for 5-6 min under a pressure of 20-25 MPa). These demanding bonding conditions are not suitable for the industrial implementation of the process and can lead to plastic deformation of the base materials.

Reactive multilayer thin films are an alternative for reducing the temperature and/or the pressure needed for diffusion bonding, since these multilayers can simultaneously improve the diffusivity, due to their nanocrystalline nature and high density of defects, and can also act as a local heat source, as the result of the heat released by the exothermic reaction of the multilayers to form intermetallic compounds [13-23]. Previous studies [23] have shown that Ni/Al multilayers are effective in the diffusion bonding of TiAl to steel. The use of these multilayers in this process allows lower joining conditions. However, these joints present unbonded areas, which impair the shear strength. The process could be rendered more effective by improving the contact of mating surfaces, which can be achieved by the use of different multilayer systems.

In this context, the main objective of this study is the diffusion bonding of TiAl alloy to AISI 310 austenitic stainless steel using Ni/Ti reactive multilayers. Although this multilayer system is less exothermic than others, such as $\mathrm{Ni} / \mathrm{Al}$, it has been successfully used in dissimilar joining of $\mathrm{NiTi}$ alloy to $\mathrm{Ti}_{6} \mathrm{Al}_{4} \mathrm{~V}$ [24]. The present study centers on the microstructural characterization of the interface and on the mechanical characterization of the joints. Interface characterization was performed by scanning electron microscopy (SEM), energy dispersive X-ray spectroscopy (EDS), electron backscatter diffraction (EBSD), transmission electron microscopy (TEM) and selected area electron diffraction (SAED), high resolution TEM (HRTEM) and Fast Fourier transform (FFT); mechanical properties were evaluated by nanoindentation and shear strength tests.

\section{Materials and Methods}

\subsection{Materials}

The base materials used in this investigation were $\mathrm{TiAl}(\mathrm{Ti}-45 \mathrm{Al}-5 \mathrm{Nb}$ at. \%) and AISI 310 austenitic stainless steel (25Cr-20Ni-0.25C wt. \%).

$\mathrm{Ni} / \mathrm{Ti}$ multilayers were used as an interlayer for diffusion bonding between these two base materials. $\mathrm{Ni} / \mathrm{Ti}$ multilayer thin films with $\sim 2.5 \mu \mathrm{m}$ total thickness were deposited onto the base materials (substrates) by d.c. magnetron sputtering from titanium (99.99\% pure) and nickel (93 wt. \%Ni, 7 wt. \%V) targets. In the presence of vanadium, the Ni target becomes nonmagnetic, resulting in more stable depositions. Before entering the deposition chamber, the surfaces of the base materials were ground using SiC abrasive papers, followed by polishing down to $1 \mu \mathrm{m}$ diamond suspension. The final polishing was carried out using colloidal silica. The samples were cleaned in ultrasound bath in acetone and ethanol. After attaining a base pressure of $\sim 5 \times 10^{-4} \mathrm{~Pa}$, the depositions were carried out at an argon pressure of $0.25 \mathrm{~Pa}$. The targets' power densities were adjusted in order to obtain near equiatomic average chemical composition. To avoid heating during deposition, the base materials were mounted in a thick rotating copper block, which acts as a heat sink. With this procedure the deposition temperature remains close to $100{ }^{\circ} \mathrm{C}$. Multilayer thin films with 30 and $60 \mathrm{~nm}$ bilayer thickness (modulation period) were prepared by varying the substrates' rotation speed with the Ti and Ni targets operating simultaneously. During one rotation the substrates pass once in front of the $\mathrm{Ti}$ target and once in front of the $\mathrm{Ni}$ target, giving rise to a bilayer ( $\mathrm{Ti}$ layer $+\mathrm{Ni}$ layer). After several rotations a stack of bilayers is obtained multilayered. When the substrates' rotation speed increases, the time that the substrates are in front of each target decreases, resulting in lower individual layer thicknesses. 


\subsection{Diffusion Bonding Experiments}

Diffusion bonding of dissimilar (TiAl to steel) joints was produced at 700 and $800{ }^{\circ} \mathrm{C}$ under pressures of 10 and $50 \mathrm{MPa}$ with a bonding time of $60 \mathrm{~min}$, in a vertical furnace with a vacuum level better than $10^{-2} \mathrm{~Pa}$. The diffusion bonding apparatus has been described elsewhere [13,17].

\subsection{Joints Characterization}

\subsubsection{Microstructural Characterization}

In order to perform the microstructural and chemical characterization of the interface, cross-sections of the joints were prepared using standard metallographic techniques. The cross-section specimens for TEM were prepared using a focused ion beam (FIB) (FEI FIB200, FEI company, Hillsboro, OR, USA), by means of the lift-out technique, at $5-30 \mathrm{keV}$. The bond interfaces were characterized by SEM (FEI company, Hillsboro, OR, USA) and analyzed by EDS (Oxford Intruments, Oxfordshire, UK), TEM (JEOL Ltd., Tokyo, Japan) and HRTEM (JEOL Ltd., Tokyo, Japan). A high resolution FEI QUANTA 400 FEG SEM (FEI company, Hillsboro, OR, USA) with EDAX Genesis X4M (Oxford Intruments, Oxfordshire, UK) was used for the SEM and EDS analyses. HRTEM images were obtained in a JEOL 2010F (JEOL Ltd., Tokyo, Japan) and a FEI Tecnai G2 (FEI company, Hillsboto, OR, USA), operating at $200 \mathrm{keV}$.

The EDS measurements were made at an accelerating voltage of $15 \mathrm{keV}$ by the standardless quantification method. The results obtained by this method provide a fast quantification with an automatic background subtraction, matrix correction and normalization to $100 \%$ for all the elements in the peak identification list.

Crystallographic information from the joint interfaces was obtained by EBSD (FEI QUANTA 400 FEG SEM). The diffraction of backscattered electrons forms a Kikuchi pattern characteristic of the underlying crystal phase. For the indexation of the patterns, the ICDD PDF2 (2006) database was used. EBSD is a surface technique, since only the topmost $50 \mathrm{~nm}$ of the specimen contributes to the diffraction pattern; for $\mathrm{Ti}$ and $\mathrm{Ni}$ the minimum lateral spread of the interaction volume ranges from 50 to $100 \mathrm{~nm}$ [25], with an accelerating voltage of $15 \mathrm{keV}$. Seeing that a careful preparation of the surface is the key factor in achieving good quality EBSD patterns, the specimens were submitted to a final chemo-mechanical polishing stage, using colloidal silica, to remove the damage and deformation of the surface of the cross-section specimens.

Selected area electron diffraction (SAED) in TEM and Fast Fourier transform (FFT) in HRTEM were also applied in order to study the crystallographic structure of the phases present at the interface.

\subsubsection{Mechanical Characterization}

The mechanical behavior was evaluated by nanoindentation using a Micro Materials-Nano hardness apparatus equipped with a Berkovich diamond indenter. Hardness and Young's modulus were determined by the Oliver and Pharr analysis method [26]. Before the depth-sensing indentation experiments, the tip area function was calibrated using fused silica as a standard. The loading/unloading experiments were run up to a maximum load of $4 \mathrm{mN}$ with a dwell bilayer thickness of $30 \mathrm{~s}$ at $0.4 \mathrm{mN}$ during unloading, for thermal drift correction. Indentation matrices with a minimum of 90 measurements were selected in order to test the joint's interface and both base materials. The scheme of the nanoindentation tests across the joints is represented in Figure 1. Prior to the indentation tests the joints were polished using standard metallographic procedures until a mirror-like surface was achieved.

The shear tests were performed at room temperature at a rate of $0.2 \mathrm{~mm} / \mathrm{min}$. The apparatus and specimens of the shear tests have been described elsewhere [23]. For each joint, three specimens were tested. SEM combined with EDS was used to identify the phases present at the fracture surfaces of the shear specimens. 


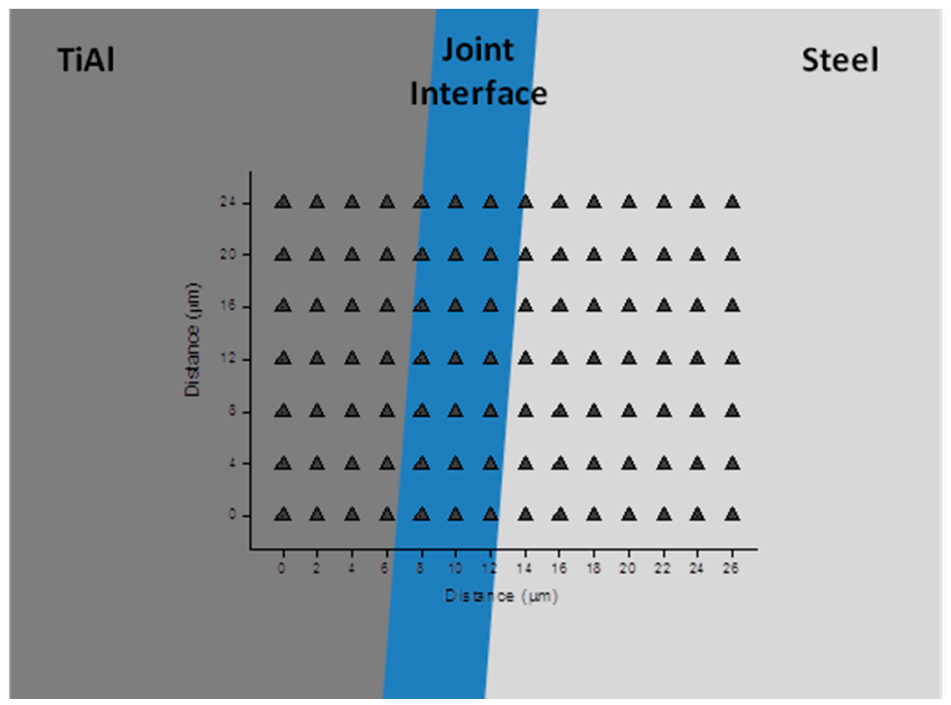

Figure 1. Scheme of the nanoindentation tests position $(\boldsymbol{\Delta})$ across the joints.

\section{Results and Discussion}

The effectiveness of using Ni/Ti multilayers to improve dissimilar bonds between TiAl and steel was assessed through microstructural and mechanical characterizations. The influence of different processing conditions $\left(700\right.$ or $800^{\circ} \mathrm{C}$ under a pressure of 10 or $50 \mathrm{MPa}$ ) and different bilayer thickness (30 and $60 \mathrm{~nm}$ ) was evaluated.

\subsection{Microstructural Characterization}

The microstructural characterization reveals that interfaces with apparent soundness were produced during the solid-state diffusion bonding of TiAl and steel using Ni/Ti multilayers. The bond between these metallic materials using $\mathrm{Ni}$ / Ti multilayers with 30 and $60 \mathrm{~nm}$ of bilayer thickness was obtained successfully at $700{ }^{\circ} \mathrm{C}$ under a pressure of $50 \mathrm{MPa}$ and at $800{ }^{\circ} \mathrm{C}$ under a pressure of $10 \mathrm{MPa}$, for $60 \mathrm{~min}$. However, some unbonded areas are observed at the edge of the samples bonded at $700{ }^{\circ} \mathrm{C}$ and at $800{ }^{\circ} \mathrm{C}$ using multilayers with $60 \mathrm{~nm}$ of bilayer thickness.

Figure 2 shows SEM images of the interface of the diffusion bonds between TiAl alloys and steel processed with $\mathrm{Ni}$ / Ti multilayers. Whatever the bilayer thickness, to achieve a sound joint at $700{ }^{\circ} \mathrm{C}$ it was necessary to apply a $50 \mathrm{MPa}$ pressure, while at $800^{\circ} \mathrm{C}$ the pressures could be reduced down to $10 \mathrm{MPa}$. The bond interfaces are thin (thickness close to $5 \mu \mathrm{m}$ ) and exhibit six layers: a thicker layer $(4 \mu \mathrm{m})$ at the center divided by a very thin dark line and, adjacent to each of the base materials, two diffusion layers with an overall thickness of not more than $1 \mu \mathrm{m}$. The thickness of the interface layers, especially those close to the base materials, increase with increasing bonding temperature and multilayer bilayer thickness. These microstructures are different from those obtained using Ni/Al multilayers [23], which exhibited a thick reaction layer near the steel substrate. From the EDS profile of Figure $2 \mathrm{~d}$ it can be seen that the interfaces mainly consist of $\mathrm{Ni}$ and $\mathrm{Ti}$, as expected. The diffusion of elements from the base material to adjacent layers is observed for all bonds. $\mathrm{Fe}$ and $\mathrm{Cr}$ are detected in zones closest to the stainless steel, while $\mathrm{Al}$ is detected in the thin layers closest to TiAl.

The identification of the phases was carried out through the combination of the EDS, EBSD, SAED and FFT results. Due to the small interaction volume of EBSD analysis, this technique is essential for the crystallographic characterization of the phases of thinner layers and for identifying the formation of nanometric phases at the interface. For phase identification in areas smaller than the EBSD resolution, TEM/SAED and HRTEM/FFT were used. 


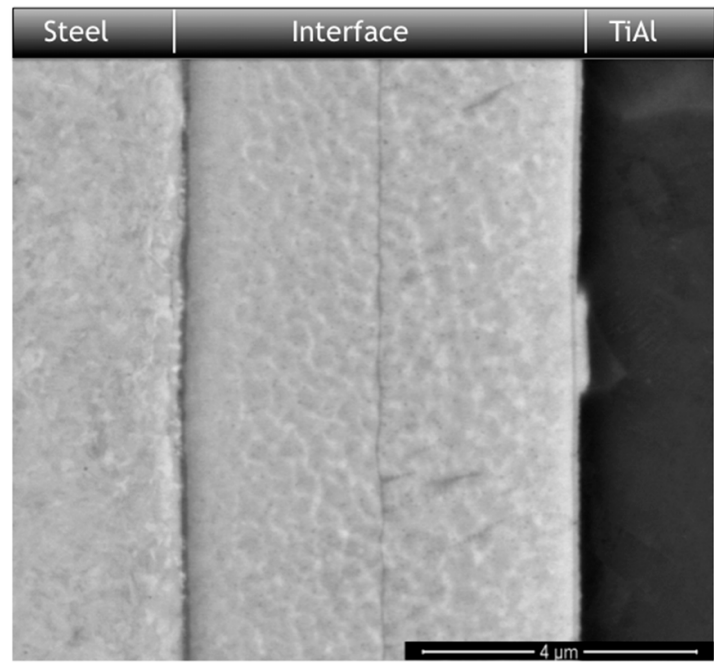

(a)

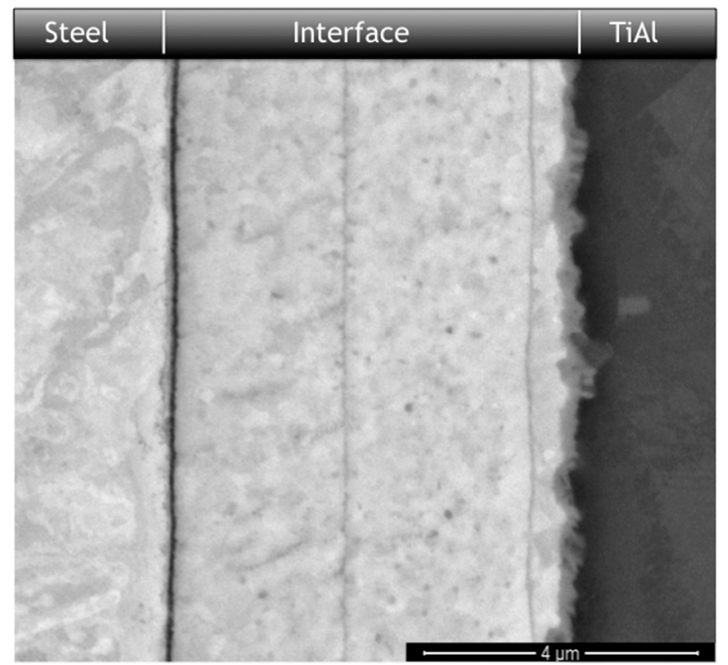

(c)

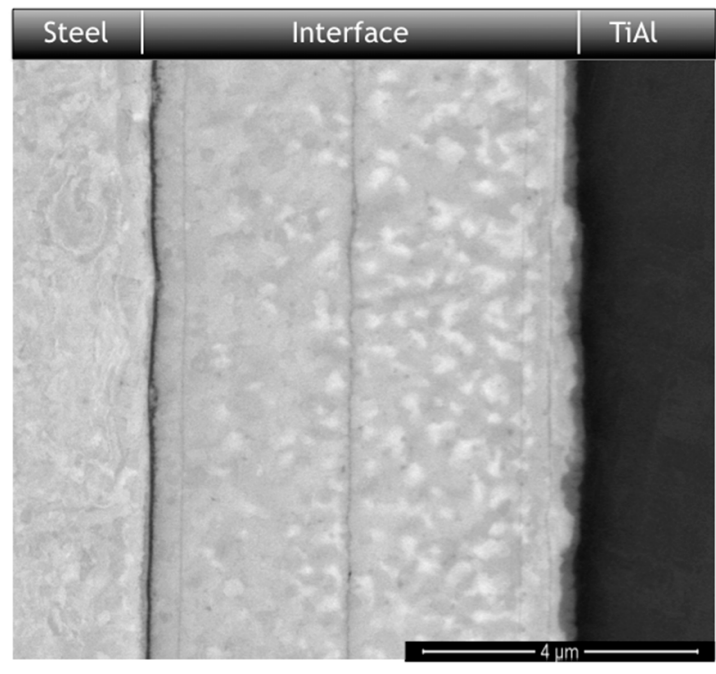

(b)
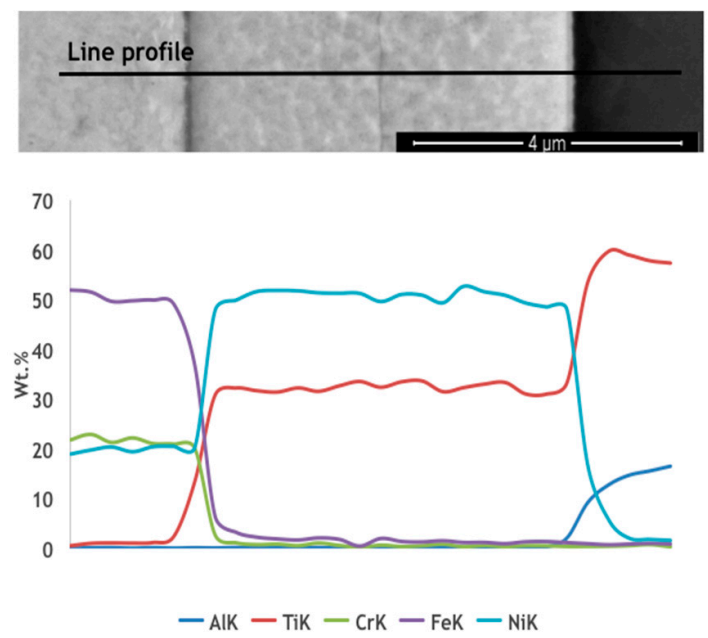

(d)

Figure 2. SEM images of the TiAl/steel joints produced at: (a) $700{ }^{\circ} \mathrm{C}$ under a pressure of $50 \mathrm{MPa}$ using Ni/Ti multilayers with $30 \mathrm{~nm}$ of bilayer thickness; (b) $800^{\circ} \mathrm{C}$ under a pressure of $10 \mathrm{MPa}$ using $\mathrm{Ni}$ /Ti multilayers with $30 \mathrm{~nm}$ of bilayer thickness; (c) $800^{\circ} \mathrm{C}$ under a pressure of $10 \mathrm{MPa}$ using Ni/Ti multilayers with $60 \mathrm{~nm}$ of bilayer thickness and (d) EDS profile across the interface presented in (a).

Figure 3 shows the EBSD patterns obtained for the thin diffusion layers close to the base materials and for the thick central zone. The greatest area of the interface comprises equiaxed grains of NiTi and $\mathrm{NiTi}_{2}$ (Kikuchi patterns 3 and 4 of Figure 3b). The indexation of the EBSD patterns of the layers close to the base materials identified the presence of AlNiTi and $\mathrm{AlNi}_{2} \mathrm{Ti}$ close to the TiAl (Kikuchi patterns 1 and 2 of Figure 3b) and $\alpha$-Fe and $\mathrm{NiTi}_{2}$ near the steel (Kikuchi patterns 5 and 6 of Figure 3b). The main differences between the interfaces produced using $\mathrm{Ni} / \mathrm{Ti}$ and $\mathrm{Ni} / \mathrm{Al}$ reactive multilayers are the phases that constitute the central area, $\mathrm{NiTi}+\mathrm{NiTi}_{2}$ for joints produced with $\mathrm{Ni} / \mathrm{Ti}$, and $\mathrm{NiAl}$ for those produced with $\mathrm{Ni} / \mathrm{Al}$. Phases richer in $\mathrm{Ni}$, such as $\mathrm{AlNi}_{2} \mathrm{Ti}$, rather than phases richer in $\mathrm{Al}$, such as $\mathrm{Al}_{2} \mathrm{NiTi}$, were also observed. The phases $\alpha$-Fe and AlNiTi were also identified in the interfaces produced using $\mathrm{Ni} / \mathrm{Al}$ multilayers [23]. 


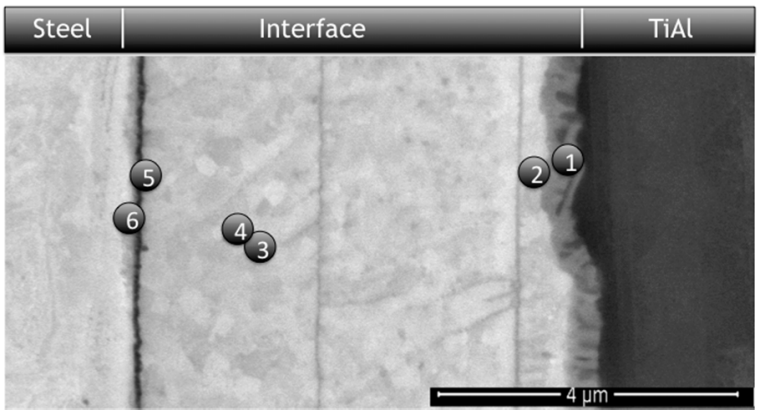

(a)
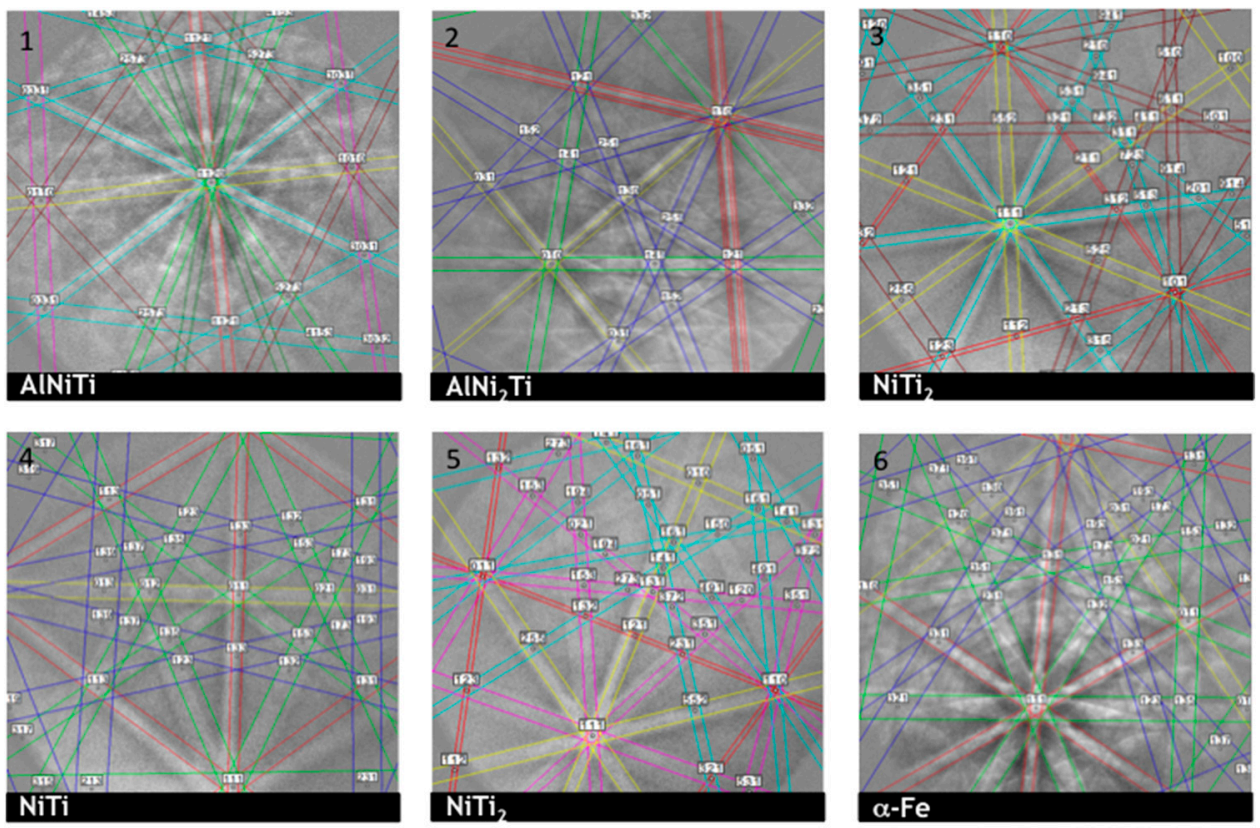

(b)

Figure 3. (a) SEM images of the $\mathrm{TiAl} /$ steel joints produced at $800^{\circ} \mathrm{C}$ under a pressure of $10 \mathrm{MPa}$ and (b) EBSD Kikuchi pattern indexation of the zones marked in (a).

Figure 4 shows the TEM and HRTEM images of the interface central zone. HRTEM images and FFT analysis revealed that this region is composed of a mixture of equiaxed grains of NiTi with nanometric $\mathrm{NiTi}_{2}$ grains divided by a very thin layer with $\mathrm{NiTi}_{2}$ aligned nanograins.

The thin layers close to the steel were also characterized by TEM and HRTEM combined with SAED and FFT, respectively, as shown in Figure 5. The TEM image (Figure 5a) of these layers shows large grains adjacent to the steel identified by SAED as $\alpha$-Fe (Figure $5 b$ ) and a line of nanometric grains identified by FFT of HRTEM images as $\mathrm{Fe}_{2} \mathrm{Ti}$ (Figure $5 \mathrm{c}$ ) and $\mathrm{NiTi}_{2}$ (Figure $5 \mathrm{~d}$ ).

In summary, the interface is composed mainly of $\mathrm{NiTi}$ and $\mathrm{NiTi}_{2}$ phases, formed during the multilayer reaction. In addition, thin layers of $\alpha-\mathrm{Fe}$ and $\mathrm{Fe}_{2} \mathrm{Ti}+\mathrm{NiTi}_{2}$ were identified close to the steel while AlNiTi and $\mathrm{AlNi}_{2} \mathrm{Ti}$ were detected close to the TiAl base material, resulting from the interdiffusion of multilayer and base materials. 


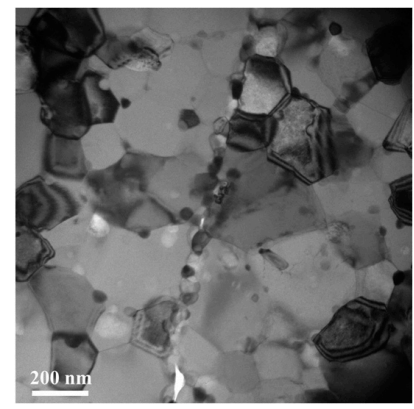

(a)

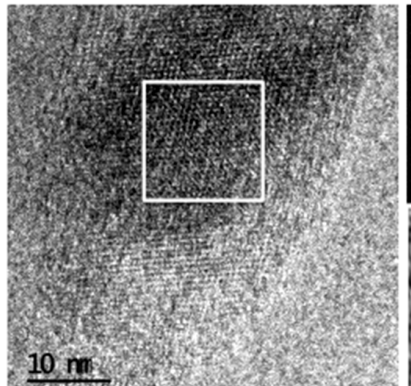

(c)
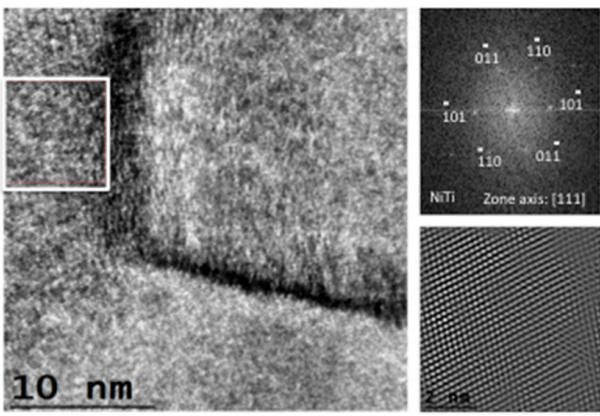

(b)

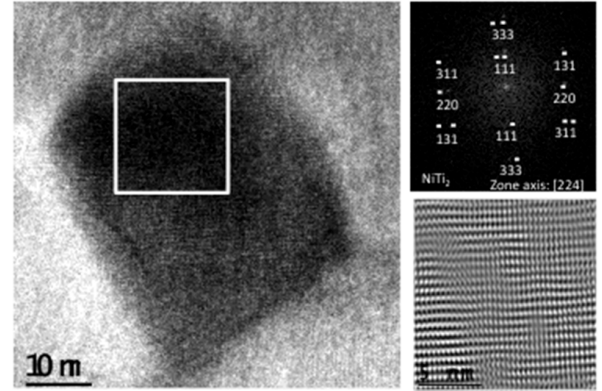

(d)

Figure 4. (a) TEM image of the interface central zone of a TiAl/steel joint produced at $800{ }^{\circ} \mathrm{C}$ using $\mathrm{Ni}$ /Ti multilayers with $30 \mathrm{~nm}$ of bilayer thickness; (b) and (c) HRTEM images and FFT indexation as $\mathrm{NiTi}$ and $\mathrm{NiTi}_{2}$ grains at the center of the joint interface; and (d) HRTEM images and FFT indexation as $\mathrm{NiTi}_{2}$ of a nanometric grain at the central line.

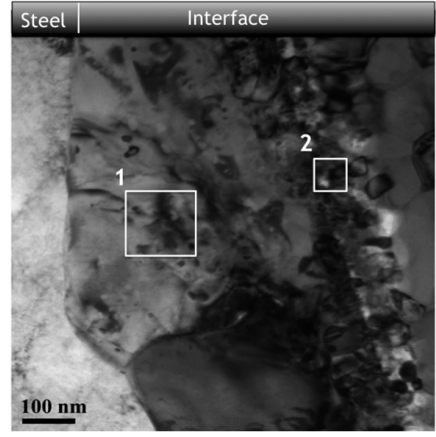

(a)

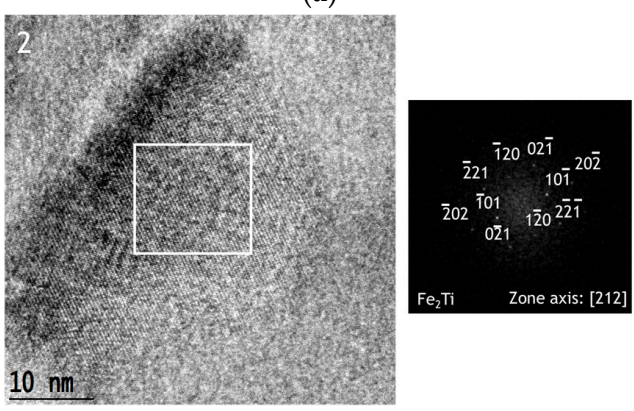

(c)
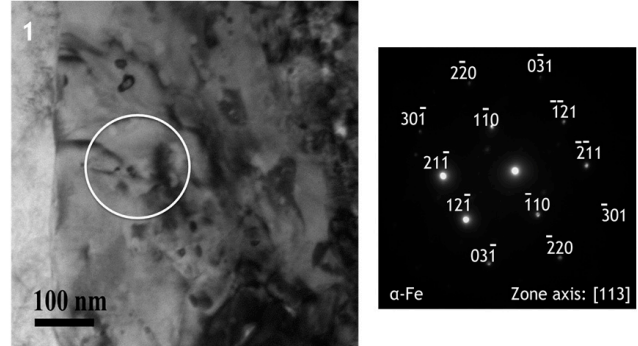

(b)

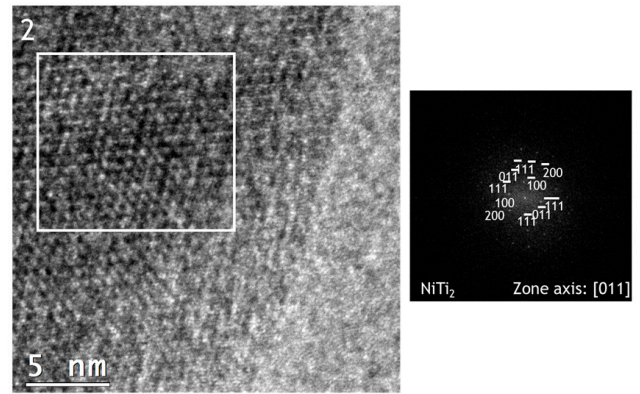

(d)

Figure 5. (a) TEM image of the zone close to the steel; (b) TEM images and SAED indexation as $\alpha$-Fe of a grain at the region marked as 1 in (a); and (c) HRTEM images and FFT indexation as $\mathrm{Fe}_{2} \mathrm{Ti}$ of a grain at the region marked as 2 in (a). 


\subsection{Mechanical Characterization}

The mechanical characterization of the diffusion bonds was performed by nanoindentation and shear tests.

Figure 6 shows the hardness and reduced Young's modulus $(E r)$ distribution maps for the joints produced at $800{ }^{\circ} \mathrm{C}$ using the multilayers with $30 \mathrm{~nm}$ bilayer thickness. The interface of the joints shows hardness values similar to those of the base materials with the exception of the thin layers close to the base materials, which are harder, in particular on the steel side. These layers exhibit a high hardness value of about 10-12 GPa. These values may be associated with the formation of $\mathrm{AlNiTi}, \mathrm{AlNi}_{2} \mathrm{Ti}$ and $\mathrm{Fe}_{2} \mathrm{Ti}$ intermetallics together with nanometric microstructures. In the diffusion bonding of these materials with $\mathrm{Ni}$ / Al multilayers, similar results were observed. The reduced Young's modulus maps clearly reproduce the phase variations across the base materials and diffusion bond, with the joint interface and the diffusion layers perfectly identifiable. According to the nanoindentation results the interface has a lower Young's modulus ( $E r \approx 85-120 \mathrm{GPa})$ in comparison with the base materials $\left(E r_{\mathrm{TiAl}} \approx 185-210 \mathrm{GPa}\right.$ and $\left.E r_{\text {steel }} \approx 210-260 \mathrm{GPa}\right)$, which was expected due to the different phases that compose the interface. The variation of the $E r$ values obtained by nanoindentation is in accordance with the Young's modulus values found in the available literature $\left(E_{\text {stainless steel }}>E_{\mathrm{TiAl}}>\right.$ $\left.E_{\mathrm{NiTi}}>E_{\mathrm{NiTi} 2}\right)[27,28]$.

The mechanical characterization of the diffusion bonds was also performed by shear tests. Table 1 shows the values of shear strength of the bonds produced. The macroscopic images of the fracture surfaces are present in Figure 7. These images show that the fracture always begins at the interface.

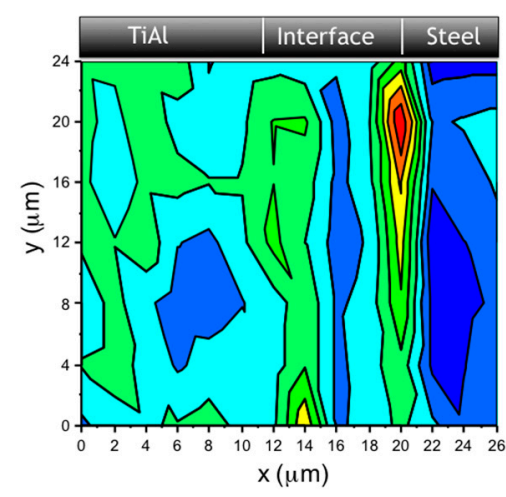

(a)
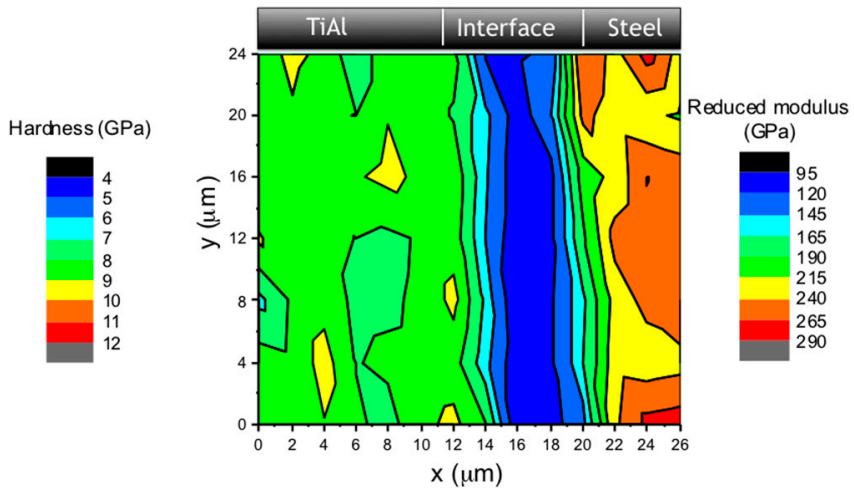

(b)

Figure 6. (a) Hardness and (b) reduced Young's modulus distribution maps of the joint produced at $800{ }^{\circ} \mathrm{C}$ using a Ni/Ti multilayer with $30 \mathrm{~nm}$ of bilayer thickness.

Table 1. Shear strength values of $\mathrm{TiAl} /$ steel joints produced using Ni/Ti multilayers.

\begin{tabular}{cccccc}
\hline $\begin{array}{c}\text { Bilayer Thickness } \\
(\mathbf{n m})\end{array}$ & $\begin{array}{c}\text { Bonding Conditions } \\
\text { (Temp./Time/Pressure) }\end{array}$ & Shear Strength Values (MPa) & $\begin{array}{c}\text { Average Shear } \\
\text { Strength (MPa) }\end{array}$ \\
\hline 30 & $700^{\circ} \mathrm{C} / 60 \mathrm{~min} / 50 \mathrm{MPa}$ & 44 & 68 & 50 & 54 \\
30 & $800^{\circ} \mathrm{C} / 60 \mathrm{~min} / 10 \mathrm{MPa}$ & 216 & 225 & 231 & 225 \\
60 & $800^{\circ} \mathrm{C} / 60 \mathrm{~min} / 10 \mathrm{MPa}$ & 66 & 99 & 83 & 83 \\
\hline
\end{tabular}

The highest shear strength value of $225 \mathrm{MPa}$ was obtained for the diffusion bonding of TiAl and steel using Ni/Ti multilayers with $30 \mathrm{~nm}$ of bilayer thickness at $800^{\circ} \mathrm{C}$ for 60 min under a pressure of $10 \mathrm{MPa}$. 


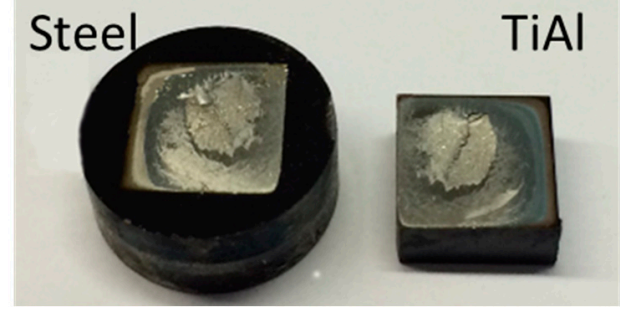

(a)

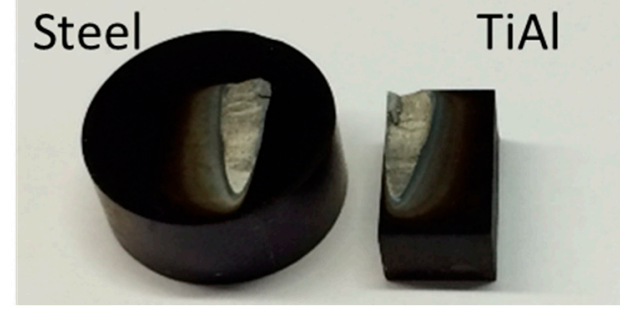

(b)

Figure 7. Macroscopic images of fracture surfaces of shear test specimens of the joints produced at $800{ }^{\circ} \mathrm{C}$ using Ni/Ti multilayers with: (a) $30 \mathrm{~nm}$ and (b) $60 \mathrm{~nm}$ of bilayer thickness.

The microstructural features and hardness distribution across the interfaces are similar for all tested conditions and cannot explain the lower strength of the joints produced at 700 and $800{ }^{\circ} \mathrm{C}$ using multilayers with $60 \mathrm{~nm}$ of bilayer thickness. The higher shear strength of the joints produced at $800^{\circ} \mathrm{C}$ with $30 \mathrm{~nm}$ bilayer thickness may be explained by a smaller unbonded region, which is clearly observed in Figure 7.

From the shear strength results it can be concluded that the use of Ni/Ti multilayers with $30 \mathrm{~nm}$ of bilayer thickness provides advantages in solid-state diffusion bonding of steel to TiAl in comparison with the more reactive $\mathrm{Ni} / \mathrm{Al}$ multilayers that present an average shear strength of $144 \mathrm{MPa}$ [23]. This may be associated with the mechanical properties of the phases formed at the interface; with the use of $\mathrm{Ni} / \mathrm{Al}$ multilayers, the interface comprises essentially NiAl, which is harder and has a higher elastic modulus than the $\mathrm{NiTi}$ and $\mathrm{NiTi}_{2}$ that form when the $\mathrm{Ni} / \mathrm{Ti}$ multilayers are used.

Diffusion bonding of TiAl to steel using Ni/Ti multilayers can be performed under lower temperature and produces joints with higher shear strength values than the ones without the interlayer and with $\mathrm{Ni} / \mathrm{Al}$ multilayers.

\section{Conclusions}

Diffusion bonding of TiAl alloys to stainless steel can be enhanced by the use of Ni/Ti multilayers as interlayers. The use of these multilayers enables the production of sound joints at $800^{\circ} \mathrm{C}$ for $60 \mathrm{~min}$ under a pressure of $10 \mathrm{MPa}$ and multilayers with $30 \mathrm{~nm}$ of bilayer thickness with an average shear strength of $225 \mathrm{MPa}$. The joints are produced at a lower temperature than those required to diffusion bond TiAl to steel without multilayers and have higher strength than those obtained with $\mathrm{Ni} / \mathrm{Al}$ multilayers. The interfaces are mainly composed of $\mathrm{NiTi}$ and $\mathrm{NiTi}_{2}$ grains showing thin layers of $\alpha$-Fe and $\mathrm{Fe}_{2} \mathrm{Ti}+\mathrm{NiTi}_{2}$ close to the steel and AlNiTi and $\mathrm{AlNi}_{2} \mathrm{Ti}$ close to the TiAl alloy.

Acknowledgments: This study was supported by the Portuguese Foundation for Science and Technology through the SFRH/BDP/109788/2015 grant and UID/EMS/00285/2013 project. The authors are grateful to CEMUP-Centro de Materiais da Universidade do Porto for expert assistance with SEM.

Author Contributions: S. Simões implemented and conducted the diffusion bonding experiments and the shear tests; A.S. Ramos and M.T. Vieira produced and characterized the multilayers and performed the nanoindentation tests; S. Simões, F. Viana and M.F. Vieira characterized the interfaces and analyzed and discussed the results; all the authors participated in the design of the experiments and cooperated in writing this paper.

Conflicts of Interest: The authors declare no conflict of interest.

\section{References}

1. Shiue, R.K.; Wu, S.K.; Chem, S.Y. Infrared brazing of TiAl using Al-based braze alloys. Intermetallics 2003, 11, 616-671. [CrossRef]

2. Çam, G.; Ípekoglu, G.; Bohm, K.H.; Koçak, M. Investigation into the microstructure and mechanical properties of diffusion bonded TiAl alloys. J. Mater. Sci. 2006, 41, 5273-5282. [CrossRef] 
3. Kim, Y.W. Ordered intermetallic alloys, Part III: Gamma-titanium aluminides. JOM 1994, 46, 30-39. [CrossRef]

4. Dimiduk, D.M. Gamma titanium aluminide alloys-An assessment within the competition of aerospace structural materials. Mater. Sci. Eng. A 1999, 263, 281-288. [CrossRef]

5. Loria, E.A. Quo vadis gamma titanium aluminide. Intermetallics 2001, 9, 997-1001. [CrossRef]

6. Cao, J.; Qi, J.; Song, X.; Feng, J. Welding and joining of titanium aluminides. Materials 2014, 7, 4930-4962. [CrossRef]

7. Noda, T.; Shimizu, T.; Okabe, M.; Iikubo, T. Joining of TiAl and steels by induction brazing. Mater. Sci. Eng. A 1997, 239-240, 613-618. [CrossRef]

8. Dong, H.; Yang, Z.; Yang, G.; Dong, C. Vacuum brazing of TiAl alloy to 40Cr steel with $\mathrm{Ti}_{60} \mathrm{Ni}_{22} \mathrm{Cu}_{10} \mathrm{Zr}_{8}$ alloy foil as filler metal. Mater. Sci. Eng. A 2013, 561, 252-258. [CrossRef]

9. He, P.; Feng, J.C.; Zhang, B.G.; Qian, Y.Y. Microstructure and strength of diffusion-bonded joints of TiAl base alloy to steel. Mater. Charact. 2002, 48, 401-406. [CrossRef]

10. He, P.; Feng, J.C.; Zhang, B.G.; Qian, Y.Y. A new technology for diffusion bonding intermetallic TiAl to steel with composite barrier layers. Mater. Charact. 2003, 50, 87-92. [CrossRef]

11. Han, W.; Zhang, J. Diffusion bonding between TiAl based alloys and steels. J. Mater. Sci. Technol. 2001, 17, 191-192.

12. He, P.; Yue, X.; Zhang, J.H. Hot pressing diffusion bonding of a titanium alloy to a stainless steel with an aluminum alloy interlayer. Mater. Sci. Eng. A 2008, 486, 171-176. [CrossRef]

13. Duckham, A.; Spey, S.J.; Wang, J.; Reiss, M.E.; Weihs, T.P.; Besnoin, E.; Knio, O.M. Reactive nanostructured foil used as a heat source for joining titanium. J. Appl. Phys. 2004, 96, 2336-2342. [CrossRef]

14. Ramos, A.S.; Vieira, M.T.; Duarte, L.; Vieira, M.F.; Viana, F.; Calinas, R. Nanometric multilayers: A new approach for joining TiAl. Intermetallics 2006, 14, 1157-1162. [CrossRef]

15. Duarte, L.I.; Ramos, A.S.; Vieira, M.F.; Viana, F.; Vieira, M.T.; Koçak, M. Solid-state diffusion bonding of gamma-TiAl alloys using Ti/Al thin films as interlayers. Intermetallics 2006, 14, 1151-1156. [CrossRef]

16. Ramos, A.S.; Vieira, M.T.; Simões, S.; Viana, F.; Vieira, M.F. Joining of superalloys to intermetallics using nanolayers. Adv. Mater. Res. 2009, 59, 225-229. [CrossRef]

17. Simões, S.; Viana, F.; Ventzke, V.; Koçak, M.; Ramos, A.S.; Vieira, M.T.; Vieira, M.F. Diffusion bonding of TiAl using Ni/Al multilayers. J. Mater. Sci. 2010, 45, 4351-4357. [CrossRef]

18. Simões, S.; Viana, F.; Koçak, M.; Ramos, A.S.; Vieira, M.T.; Vieira, M.F. Diffusion bonding of TiAl using reactive Ni/Al nanolayers and Ti and Ni foils. Mater. Chem. Phys. 2011, 128, 202-207. [CrossRef]

19. Simões, S.; Viana, F.; Koçak, M.; Ramos, A.S.; Vieira, M.T.; Vieira, M.F. Microstructure of reaction zone formed during diffusion bonding of TiAl with Ni/Al multilayer. J. Mater. Eng. Perform. 2012, 21, 678-682. [CrossRef]

20. Namazu, T.; Takemoto, H.; Fujita, H.; Nagai, Y.; Inoue, S. Self-propagating explosive reactions in nanostructured $\mathrm{Al} / \mathrm{Ni}$ multilayer films as a localized heat process technique for MEMS. In Proceedings of 19th IEEE International Conference on Micro Electro Mechanical Systems, Istanbul, Turkey, 22-26 January 2006; pp. 286-289.

21. Zhang, J.; Wu, F.S.; Zou, J.; An, B.; Liu, H. Al/Ni multilayer used as a local heat source for mounting microelectronic components. In Proceedings of the International Conference on Electronic Packaging Technology \& High Density Packaging, ICEPT-HDP 09, Beijing, China, 10-13 August 2009; pp. 838-842.

22. Simões, S.; Viana, F.; Ramos, A.S.; Vieira, M.T.; Vieira, M.F. Anisothermal solid-state reaction of $\mathrm{Ni} / \mathrm{Al}$ nanometric multilayer. Intermetallics 2011, 19, 350-356. [CrossRef]

23. Simões, S.; Viana, F.; Ramos, A.S.; Vieira, M.T.; Vieira, M.F. Reaction-assisted diffusion bonding of TiAl alloy to steel. Mater. Chem. Phys. 2016, 161, 73-82. [CrossRef]

24. Simões, S.; Viana, F.; Ramos, A.S.; Vieira, M.T.; Vieira, M.F. Reaction Zone Formed during Diffusion Bonding of TiNi to $\mathrm{Ti}_{6} \mathrm{Al}_{4} \mathrm{~V}$ using Ni/Ti Nanolayers. J. Mater. Sci. 2013, 48, 7718-7727.

25. Kim, J.S.; LaGrange, T.; Reed, B.W.; Taheri, M.L.; Armstrong, M.R.; King, W.E.; Browning, N.D.; Campbell, G.H. Imaging of transient structures using nanosecond in situ TEM. Science 2008, 321, 1472-1475. [CrossRef] [PubMed]

26. Oliver, W.C.; Pharr, G.M. An improved technique for determining hardness and elastic modulus using load and displacements sensing indentation experiments. J. Mater. Res. 1992, 7, 1564-1583. [CrossRef] 
27. Kipp, D.O. Material Data Sheets. MatWeb, LLC, 2010; Online version. Available online: http:/ / www.matweb.com (accessed on 25 April 2016).

28. Toprek, D.; Belosevic-Cavor, J.; Koteski, V. Ab initio studies of the structural, elastic, electronic and thermal properties of $\mathrm{NiTi}_{2}$ intermetallic. J. Phys. Chem. Solids 2015, 85, 197-205. [CrossRef]

(c) 2016 by the authors; licensee MDPI, Basel, Switzerland. This article is an open access article distributed under the terms and conditions of the Creative Commons Attribution (CC-BY) license (http:/ / creativecommons.org/licenses/by/4.0/). 